OPEN ACCESS

Edited by: Ru-Ping Dai,

Central South University, China

Reviewed by:

Roberto Tonelli,

University Hospital of Modena, Italy

Jiapeng Huang,

University of Louisville, United States

Zhaolan Hu,

Stanford University, United States

*Correspondence:

Daniel K. Goyal

daniel.goyal@gha.gi

Specialty section:

This article was submitted to

Intensive Care Medicine and

Anesthesiology,

a section of the journal

Frontiers in Medicine

Received: 15 June 2020 Accepted: 23 November 2020 Published: 06 January 2021

Citation:

Goyal DK, Mansab F and Bhatti S (2021) Room to Breathe: The Impact of Oxygen Rationing on Health

Outcomes in SARS-CoV2.

Front. Med. 7:573037.

doi: $10.3389 /$ fmed.2020.573037

\section{Room to Breathe: The Impact of Oxygen Rationing on Health Outcomes in SARS-CoV2}

\author{
Daniel K. Goyal ${ }^{1,2,3 *}$, Fatma Mansab ${ }^{1,3}$ and Sohail Bhatti ${ }^{1,3,4}$ \\ ${ }^{1}$ COVID-19 Research Group, Public Health Gibraltar, Gibraltar Health Authority, Gibraltar, United Kingdom, ${ }^{2}$ Department of \\ Medicine, Acute General Medicine, St. Bernard's Hospital, Gibraltar, United Kingdom, ${ }^{3}$ Department of Postgraduate \\ Medicine, University of Gibraltar, Gibraltar, United Kingdom, ${ }^{4}$ Director of Public Health, Gibraltar Health Authority, Gibraltar, \\ United Kingdom
}

As the primary surge of coronavirus disease 2019 (COVID-19) wanes in many countries, it is important to reconsider best practice. More cases, probably the majority of cases, are yet to come. Hopefully, during this next phase, we will have more time, more resources, and more experience from which to affect better outcomes. Here, we examine the compromised oxygen strategy that many nations followed. We explore the evidence related to such strategies and discuss the potential mortality impact of delaying oxygen treatment in COVID-19 pneumonia.

Keywords: guidelines, hypoxia, SARS - CoV-2, treatment, oxygen, COVID-19, healthcare, rationing

\section{INTRODUCTION}

Severe acute respiratory syndrome coronavirus 2 (SARS-CoV2) is a new viral infection in humans, causing what has been termed COVID-19 (coronavirus disease 2019). For many, the illness is mild, often causing an upper respiratory tract infection (URTI). For a few, the disease progresses to a lower respiratory tract infection, and invariably, chest imaging shows this as a viral pneumonia (1). Again, most recover, but for some, the disease does not abate, and they go on to develop acute respiratory distress syndrome (ARDS) (2).

The rate of progression from mild (URTI or other viral constellation) to severe (pneumonia) to critical (ARDS) is not entirely clear. Estimates range between 76 and $99 \%$ for mild disease, 1 and $24 \%$ for progressive pneumonic illness, and 0.6 and $13 \%$ for further progression to ARDS. The true mortality rate also remains relatively unclear with estimates of $<1 \%$ to over $10 \%$ and is likely to depend in part on access to appropriate health care (3-5).

Wuhan (China), Lombardy (Italy), Madrid (Spain), London (UK), and New York (USA) each experienced a surge of cases to the point where the local health services struggled to provide optimal care to all patients (6). During this "surge" period, the decision was made by some healthcare systems to ration oxygen, i.e., to delay the initiation of oxygen and to permit patients to maintain lower oxygen levels than would normally be accepted (7).

Such "conservative" oxygen strategies continue in many parts of the world despite adequate healthcare capacity and resources (8-12). The concern then is that patients are going without optimal treatment not due to excess demand on the health service but due to a practice established during actual or feared resource limitations.

To appreciate the impact of oxygen rationing on health outcomes during the COVID-19 pandemic, the evidence behind the "conservative" oxygen approach was examined, specifically for mortality outcomes. 


\section{THE GUIDELINES}

The normal, mean oxygen saturations ( $\mathrm{SpO} 2)$ across an adult population has been reported as $97.5 \%( \pm 1.5 \%)$ within a mean age of 63 years (range, $38-83$ years). Approximately $7 \%$ of the population is classified as hypoxic at baseline ( $\mathrm{SpO} 2<95 \%)(13)$.

Current treatment guidelines for community acquired pneumonia, including viral pneumonia, recommend commencement of supplemental oxygen when $\mathrm{SpO} 2$ falls below $95 \%$ and recommend a maintenance target $\mathrm{SpO} 2$ of $94-98 \%$ in the majority of patients (14).

The recent World Health Organization (WHO) COVID19 treatment guidelines recommend to maintain target $\mathrm{SpO} 2$ of $>90 \%$ in adults and between 92 and $95 \%$ in pregnant women (15).

The COVID-19 guidelines produced by the Surviving Sepsis Campaign (SSC) suggest (at recommendation 23) that supplemental oxygen should be commenced when a patient's $\mathrm{SpO} 2$ is $<92 \%$. The guidelines also recommend a "conservative oxygen" strategy for all patients with COVID-19 aiming for target $\mathrm{SpO} 2$ between 92 and $96 \%$. The panel go on to explain how their concern for potential resource limitations influenced the clinical recommendations (16):

"Considering the associated patient harm at the extremes of $\mathrm{SpO} 2$ targets and the increased cost of liberal oxygen use, as well as the potential to reduce equity if oxygen resources are depleted, the panel issued a strong recommendation against using oxygen to target $\mathrm{SpO} 2>96 \%$, and a strong recommendation to avoid lower values ( $\mathrm{SpO} 2<90 \%)$ " (16).

\section{THE EVIDENCE BEHIND THE "CONSERVATIVE OXYGEN" STRATEGY}

The WHO references its own general pediatric guidelines. The SSC guidelines reference the five most pertinent publications, reviewed below (17-21).

The first was a retrospective analysis published in March 2020, investigating the optimal oxygen saturations ( $\mathrm{SpO} 2)$ for patients admitted to Intensive Care Units (ICU). The investigators analyzed over 35,000 patients and concluded that the optimum oxygen range for patients in ICUs was $94-98 \%$. Patients who spent only $40 \%$ in the optimal range had a $50 \%$ increased mortality than those who spent $80 \%$ in the optimal range of SpO2 94-98\% (17). The investigators corrected for a number of confounders, including disease severity.

The second study referenced by the SSC guidelines is the Improving Oxygen Therapy in Acute Illness (IOTA) metaanalysis examining liberal vs. conservative oxygen use in patients with a variety of conditions [stroke $(n=8)$, myocardial infarction $(n=6)$, cardiac arrest $(n=2)$, acute appendicitis $(n=2)$, critical care $(n=2)$, sepsis $(n=1)$, septic shock $(n=1)$, perforated viscus $(n=1)$, limb ischemia $(n=1)$, and traumatic brain injury $(n=$ 1)] (18).

None of the studies reviewed in the IOTA meta-analysis examined pneumonia. Perhaps of some relevance are the two critical care studies analyzed $(22,23)$.
The first was a randomized controlled trial (RCT) examining the effect of conservative oxygen (defined in this study as $\mathrm{SpO} 2$ of 94-98\%) and liberal oxygen (97-100\%) on mortality in an ICU. The supplementary data suggest that the liberal group was significantly more acutely unwell on admission than the conservative group (for example, respiratory failure of 30.2 vs. $17.4 \%$; mechanical ventilation at admission of 27 vs. $16.1 \%$; liver failure of 33.3 vs. $22.5 \%$; and renal failure of 45.7 vs. $25 \%$ ). This RCT reported improved mortality in the conservative, $\mathrm{SpO} 2$ 94-98\% group (22).

The second critical care study examined in the IOTA metaanalysis was a pilot RCT study examining conservative oxygen targets (88-92\%) vs. liberal oxygen targets $(>96 \%)$ in patients on mechanical ventilation $(n=103)$. It is of note that $21 \%$ of the conservative arm were chronic obstructive pulmonary disease (COPD) patients vs. only $10 \%$ of patients in the liberal oxygen arm. The mean oxygen levels in each group over the study period were $93.4 \%$ in the conservative arm and $97 \%$ in the liberal arm. The study did not identify any difference in mortality between the two groups (23).

All of the other trials analyzed in the IOTA meta-analysis had little relevance to optimum oxygen saturations in patients with pneumonia or ARDS. Most of the studies were testing supplemental oxygen as a potential treatment (for example in stroke or myocardial infarction). Further, patients who were hypoxic were excluded from almost half the trials analyzed. The mean oxygen saturation (where the data was available) in the liberal group was $96.4 \%$, and in the conservative group was $96.7 \%$. Following trial sequential analysis, the authors concluded that hyperoxemia carried an increased 1-year mortality risk [hazard ratio (HR), 1.11 (95\% CI 1.00-1.24), $p=0.05$ ]. The authors go on to suggest that the ideal target $\mathrm{SpO} 2$ for all admissions might be $94-96 \%$. With the regression analysis likely powered by the true hyperoxemic trials and the marked heterogeneity within the studies analyzed, the reason for the authors equivocation seems justified (18).

The third paper referenced in the SSC guidelines was an opinion paper making recommendations based on the IOTA meta-analysis (19).

The fourth paper was an RCT examining conservative (90$96 \%)$ vs. normal oxygen targets during mechanical ventilation in the ICU $(n=1,000)$. Over 22 days, the conservative group spent $28 \mathrm{~h}$ more with an Fio2 of $<0.21$ than the usual group, and a total of $22 \mathrm{~h}$ less time above $\mathrm{SpO} 2$ of $96 \%$ than the usual group. The mean oxygen level range over the course of the study were $\mathrm{PaO} 2$ of $80-85 \mathrm{mmHg}(\sim \mathrm{SpO} 2$ of $95-96 \%)$ in the conservative group and $\mathrm{PaO} 2$ of $90-95 \mathrm{mmHg}$ ( $\sim \mathrm{SpO} 2$ of $96-97 \%)$ in the normal group. There was no significant mortality difference noted (20).

The final paper referenced was an RCT into the use of conservative oxygen levels (sats 88-92\%) vs. liberal oxygen use (sats $>96 \%)$ in ARDS $(n=205)$. Relatively strict adherence to target saturations were observed with a mean range of $\mathrm{SpO} 2$ of $92-93 \%$ in the conservative group vs. $95-97 \%$ in the liberal group. The study was halted due to excessive death in the conservative oxygen arm vs. the liberal arm (44.4 vs. $30.4 \% 90-$ day mortality). As well as the $23 \%$ increased ICU mortality, $27 \%$ increased 28 -day mortality, and the $50 \%$ higher 90 -day mortality, 
TABLE 1 | Relevant studies comparing conservative vs. liberal oxygen strategies in acute illness.

\begin{tabular}{|c|c|c|c|c|}
\hline Study & Methods & Findings & Comment & Suggestions \\
\hline Chu et al. (18) & $\begin{array}{l}\text { Meta-analysis (up to Oct 2017) of } \\
\text { trials comparing liberal vs. } \\
\text { conservative oxygen strategies in a } \\
\text { variety of conditions( } n=16,037 \text { ) }\end{array}$ & $\begin{array}{l}\text { "hyperoxemia" carries an increased } \\
\text { 1-year mortality risk [HR } 1.11(95 \% \mathrm{Cl} \\
1.00-1.24), p=0.05)\end{array}$ & $\begin{array}{l}\text { Heterogenous studies, } \\
\text { examining oxygen therapy mainly } \\
\text { in ischemic conditions. } \\
\text { Unreliable in relation to oxygen } \\
\text { targets in acute } \\
\text { nonischemic illness. }\end{array}$ & $\begin{array}{l}\text { Optimum target } \\
\text { saturations might } \\
\text { become } \\
\text { unfavorable above } \\
\text { SpO2 of } 94-96 \%\end{array}$ \\
\hline Girardis et al. (22) & $\begin{array}{l}\text { Single-centered, open-labeled RCT } \\
\text { Conservative (SpO2 of 94-95\%) vs. } \\
\text { liberal (SPO2 of } 97-100 \%) \text { in ICU } \\
\text { admissions of any cause ( } n=434)\end{array}$ & $\begin{array}{l}\text { Improved mortality in conservative } \\
\text { group (SpO2 of } 94-98 \%): \text { RR } 0.57 \\
\text { (95\% Cl } 0.37-0.9, p=0.01 \text { ) }\end{array}$ & $\begin{array}{l}\text { Liberal group had significantly } \\
\text { more medical problems } \\
\text { at enrolment. }\end{array}$ & $\begin{array}{l}\text { Target sats } \\
\text { of } 94-98 \%\end{array}$ \\
\hline Panwar et al. (23) & $\begin{array}{l}\text { Pilot multicenter RCT } \\
\text { SpO2 of } 88-92 \% \text { vs. } 96 \% \text { in patients } \\
\text { requiring MV of any cause }(n=103)\end{array}$ & $\begin{array}{l}\text { No difference in mortality or length of } \\
\text { ICU stay }\end{array}$ & $\begin{array}{l}21 \% \text { of the conservative group } \\
\text { had COPD vs. only } 10 \% \text { of the } \\
\text { liberal. Actual comparison was } \\
\text { SpO2 of } 93.4 \text { vs. } 97 \%\end{array}$ & Larger trial needed \\
\hline Schernthaner et al. (24) & $\begin{array}{l}\text { Retrospective observational studies } \\
\text { comparing arterial blood gases and } \\
\text { mortality in pulmonary edema and } \\
\text { heart failure }(n=475)\end{array}$ & $\begin{array}{l}\text { Increased mortality in patients with } \\
\text { pneumonia with arterial } \mathrm{PO} 2 \text { of } 150 \\
\text { vs. } 117 \mathrm{mmHG}(\mathrm{HR}=1.02 ; 95 \% \mathrm{Cl} \text { : } \\
1-1.4, p=0.02)\end{array}$ & $\begin{array}{l}\text { Pneumonia related } \\
\text { Nontrial data } \\
\text { Potentially measuring true } \\
\text { hyperoxemia effects. }\end{array}$ & $\begin{array}{l}\text { Optimal PO2 } \\
\text { calculated as } 98 \\
\mathrm{mmHg}(\text { or } \sim \mathrm{SpO} 2 \\
\text { of } 97.3 \%)\end{array}$ \\
\hline $\begin{array}{l}\text { van den Boom et al. } \\
(17)\end{array}$ & $\begin{array}{l}\text { Multicenter, retrospective } \\
\text { observational analysis of SpO2 and } \\
\text { mortality in ICU patients of any cause } \\
(n=35,000)\end{array}$ & $\begin{array}{l}\text { Increased mortality with mean SpO2 } \\
92 \text { vs. 96\% [OR, } 3.2(2.9-3.5)] . \\
\text { Increased mortality with mean SpO2 } \\
100 \text { vs. } 96 \%[\text { OR } 1.6(1.5-1.6)] \\
(n=26,723) .\end{array}$ & $\begin{array}{l}\text { Large patient numbers utilizing } \\
\text { shared datasets. } \\
\text { Not a clinical trial. }\end{array}$ & $\begin{array}{l}\text { Optimum target } \\
\text { SpO2 is } 94-98 \%\end{array}$ \\
\hline $\begin{array}{l}\text { IICU-ROX Investigators } \\
\text { the Australian New } \\
\text { Zealand Intensive Care } \\
\text { Society Clinical Trials } \\
\text { Group et al. (20) }\end{array}$ & $\begin{array}{l}\text { Multicenter, RCT SpO2 of } 92-96 \% \\
\text { vs. normal in patients requiring MV of } \\
\text { any cause }(n=1,000)\end{array}$ & $\begin{array}{l}\text { No difference in mortality or length of } \\
\text { ICU stay }\end{array}$ & $\begin{array}{l}\text { Actual Comparison was mean } \\
\text { SpO2 of } 95-96 \% \text { vs. 96-97\% }\end{array}$ & None made \\
\hline Barrot et al. (21) & $\begin{array}{l}\text { Multicenter, RCT SpO2 of } 88-92 \% \\
\text { vs. >96\%in patients with ARDS of } \\
\text { any cause }(n=205)\end{array}$ & $\begin{array}{l}\text { Study halted due to safety. } \\
\text { Significantly higher mortality in the } \\
\text { conservative oxygen group. } \\
\text { Ninety-day mortality was } 44 \% \text { in } \\
\text { conservative arm vs. } 30.4 \% \text { in } \\
\text { liberal arm. }\end{array}$ & $\begin{array}{l}\text { Actual Comparison was mean } \\
\text { SpO2 of } 92-93 \% \text { vs. 95-97\% }\end{array}$ & None made \\
\hline
\end{tabular}

RCT, randomized controlled trial; SpO2, oxygen saturations; HR, hazard ratio; RR, relative risk; OR, odds ratio (adjusted); ICU, intensive care unit; MV, mechanical ventilation.

the complications in the conservative arm included mesenteric ischemia ( 5 vs. $0 \%$ ) and cardiac arrhythmias (44 vs. $28 \%$ ). Target oxygen saturations lower than that currently recommended were shown to substantially increase mortality (21).

\section{DISCUSSION}

Instigating a "conservative oxygen" strategy as a means of healthcare rationing is likely to contribute to the higher mortality experienced during a COVID-19 "surge." The evidence for a significant increase to mortality rate was particular strong for targeting lower oxygen saturations $(<94 \%)$. The evidence of harm when restricting the upper limit of oxygen saturations (98-96\%) was less convincing (Table 1). It is of note that the recent British Thoracic Society (BTS) guidelines specifically for COVID-19 advises a target $\mathrm{SpO} 2$ of 94-98\% (25).

Hypoxia ( $\mathrm{SpO} 2<95 \%$ ) has numerous adverse health effects. In the acute setting, hypoxia increases the risk of fatal arrhythmia and end-organ damage (26). In a subacute setting, hypoxia has been shown to drive pulmonary inflammation and the systemic inflammatory response $(27,28)$ and to promote coagulation leading to an increase in thromboembolic events $(29,30)$. Long-term effects of hypoxia include ongoing cognitive impairment (31).

In relation to pneumonia specifically, delayed correction of hypoxia has been shown to lead to a more protracted and severe pneumonia, an increase in the rate of mechanical ventilation, and an increase in actual mortality $(32,33)$.

There is no evidence to suggest that the pathophysiology of COVID-19 pneumonia is exempt from these established detrimental effects of hypoxia. Indeed, there is evidence to suggest earlier correction of hypoxia in COVID-19 pneumonia may lead to improved outcomes. Shenoy et al. highlight the exacerbation of hypoxia on angiotensin-converting enzyme 2 (ACE2) upregulation and pulmonary vasoconstriction in COVID-19 pneumonia, suggesting that "permitted hypoxia" may be leading to more severe disease (34). Ackermann et al. examined autopsy specimens from influenza (H1N1) and COVID-19 cases and found a greater level of intussusceptive angiogenesis and alveolar microthrombi in COVID-19-both of which can be caused/exacerbated by hypoxia (35). It is of note that the H1N1 outbreak did not incur oxygen rationing. 
Of the large postmortem cohort studies, an Italian cohort ( $n$ $=38$ ) and a US cohort $(n=67)$ both report a hypercoaguable state with pulmonary thromboembolism in medium or small arteries in over $80 \%$ of COVID-19 lung specimens examined $(36,37)$. Both the US and Italy adopt a conservative oxygen strategy $[\mathrm{SpO} 2<92 \%$ prior to the commencement of oxygen $(10,11)]$. The largest Swiss postmortem cohort $(n=21)$, where standards of oxygen targets have been maintained (SpO2 of 94-98\%) (38), found that only 19\% had evidence of peripheral or central pulmonary thromboembolism (39). There are inadequate numbers of postmortem studies globally to generate any form of conclusions, but given that hypoxia is known to cause a hypercoaguable state, likely to be exacerbated under proinflammatory conditions, and hypoxia itself further promotes pulmonary inflammation, we should be mindful of the likelihood that delayed correction of hypoxia in COVID-19 patients increase the propensity for, and therefore damage caused by, thromboembolism of the pulmonary vasculature.

In-keeping with this, Sun et al. reported a reduction in ICU admissions and mechanical ventilation by early identification and correction of hypoxia in patients with COVID-19 (40).

While such evidence is welcomed, we must be clear that it is not a requirement for the established pneumonia guidelines to prove efficacy in COVID-19 pneumonia. Target oxygen saturations in acute illness, pneumonia, and COVID-19 pneumonia remain at $\mathrm{SpO} 2$ of $94-98 \%(14,25,41)$. In the complete absence of any evidence to support an improved outcome-or even convincing evidence of the same outcomesfor lower target oxygen saturations in COVID-19 pneumonia, and with the more recent trials showing a convincing increase in mortality of conservative oxygen strategies, clinicians must continue to advocate for improved access to care and must not accept suboptimal or harmful amendments to established standards of care, certainly not based on an evidential argument.

While the scientific evidence provides no defense for lowering target oxygen saturations in COVID-19 pneumonia, there may be local civil contingency or procurement rationale for implementing such policies. The UK-wide directive to ration oxygen to patients, issued by the National Health Service (NHS) England in April 2020, may have been such a resource-related recommendation (7). Such a directive-where the evidence for harm is substantial-poses a considerable challenge to healthcare providers. The evidence is quite clear that a delay in the initiation of oxygen to the hypoxic, pneumonic patient leads to higher rates of mechanical ventilation, prolonged hospital stays, higher mortality, and, crucially, from a civil contingency standpoint, the real possibility of an overall increased consumption of oxygen supplies. There is also no evidence to suggest that COVID19 pneumonia will differ in this regard. As such, and while we appreciate the challenging decisions relating to resource allocations, we must continue to advocate for improved access to treatment. That is, the decision to conserve oxygen and reduce target oxygen saturations in COVID-19 patients may well be made on a resource-limitation perspective, but it is done so within the fully transparent evidence that such compromise will cost lives.
The identification of the COVID-19 phenomenon of "silent hypoxia" adds further levels of complexity to frontline healthcare providers. The evidence already alluded to clearly support efforts to maintain the standards of care of COVID-19 patients to at least that afforded patients with other forms of viral pneumonia. Given that there are these "silent hypoxic" COVID-19 patients who do not complain of shortness of breath yet suffer marked hypoxia at rest, then-if the aim is to reduce mortality-we cannot rely on the self-reported symptom of breathlessness to identify those requiring further assessment and/or supplemental oxygen (42). Lower thresholds for measuring oxygen levels in patients suspected or confirmed to have COVID-19 may be prudent. This of course challenges the "stay home" approach adopted by a number of nations in favor of an "early assessment and ongoing vigilance" approach as adopted by the likes of Singapore, Australia, and Japan.

Similar to Middle East respiratory syndrome (MERS) and SARS, evidence is growing of a prolonged recovery time, and disability, following COVID-19 pneumonia (43). The largest study to date examined 548 patients more than 3 months after discharge from hospital and compared them to local controls. Half of the patients suffered prolonged symptoms (fatigue/physical decline, dyspnea, tachycardia, and alopecia), but $<10 \%$ had persistence of these symptoms at 3 months. Of considerable note is that the only acute symptom present on initial admission to hospital that was associated with persistent symptoms (fatigue/physical decline, dyspnea, and tachycardia) was shortness of breath. A further UK cohort revealed a startling $85 \%$ of patients suffering prolonged symptoms who stayed home during the initial infection suffered breathlessness $(n=164)$ (38). Prolonged hypoxia during the active infection may account for some of the more prolonged disability following COVID-19.

Many countries have not taken a "conservative" oxygen approach to COVID-19. Most notably, Singapore, Switzerland, and Austria have maintained target $\mathrm{SpO} 2$ of $>94 \%$ throughout the outbreak $(24,44) ;(45)$. Other countries with similar population burdens of total COVID-19 cases have taken a conservative oxygen approach. Most notably, the US, UK, Italy, France, and Spain have all maintained guidelines permitting a delay in the initiation of oxygen until oxygen saturations are $\leq 92 \%(8-12)$. Within the context of reduced vigilance and an overexuberant "stay home" message, the excess mortality caused by such conservative oxygen strategies are likely to be compounded further. Most certainly, patients with COVID-19 require more care and attention, not less.

The reason some nations have employed a "conservative oxygen strategy" remains largely unknown. The UK, and perhaps the US, was concerned about oxygen provisions $(7,10)$. The UK specifically was concerned with the "rate of flow" (not the actual oxygen supply). Would the system (pipes and valves) handle the increased draw? There is also the possibility that the implementation of a conservative oxygen strategy was motivated to permit more patients to be managed at home or indeed to remove them from healthcare follow-up altogether and, as such, relieve the healthcare system. No modeling regarding such an approach has been published. Indeed, failing to correct hypoxia earlier is likely to compound the pressures on the high-intensity, 
high-skilled clinical care areas (e.g., Respiratory and Intensive Care Wards).

\section{CONCLUSION}

During a surge of cases that overwhelms a local healthcare system, there will be many compromises. It is likely that some of these compromises will have an impact on morbidity and mortality. It is then important to readjust quality and standards back to optimum when a healthcare system begins to recover or, where the healthcare system continues to struggle, place greater emphasis and effort into building healthcare capacity.

A conservative oxygen approach is a compromise that carries a significant mortality impact in COVID-19 pneumonia. Just as in other pneumonias, the time taken to correct hypoxia relates to disease severity, disease burden, and mortality. As the focus shifts to re-establishing healthcare capacity, improving the identification of the hypoxic patient and improving access to

\section{REFERENCES}

1. Lim ZY, Khoo HW, Hui TCH, Kok SSX, Kwan KEL, Young BE, et al. Variable computed tomography appearances of COVID-19. Singapore Med J. (2020) 61:387-91. doi: 10.11622/smedj.2020066

2. Wu Z, McGoogan JM. Characteristics of and important lessons from the coronavirus disease 2019 (COVID-19) outbreak in China: summary of a report of 72314 cases from the Chinese Center for disease control and prevention. JAMA. (2020) 323:1239-42. doi: 10.1001/jama. 2020.2648

3. Ines S. A hundred days into the coronavirus disease (COVID-19) pandemic. Euro Surveill. (2020). 25:2000550. doi: 10.2807/1560-7917.ES.2020.25.14.2000550

4. Hu Y, Sun J, Dai Z, Deng H, Li X, Huang Q, et al. Prevalence and severity of corona virus disease 2019 (COVID-19): a systematic review and meta-analysis. J Clin Virol. (2020) 127:104371. doi: 10.1016/j.jcv.2020. 104371

5. Ioannidis JAP, Axfors C, Despina G. Contopoulos-ioannidis populationlevel COVID-19 mortality risk for non-elderly individuals overall and for non-elderly individuals without underlying diseases in pandemic epicenters. medRxiv [Preprint]. (2020). doi: 10.1101/2020.04.05.20054361

6. Frederik V, Elise K, Philippe B. Indications for healthcare surge capacity in European countries facing an exponential increase in coronavirus disease (COVID-19) cases. Euro Surveill. (2020). 25:2000323. doi: 10.2807/1560-7917.ES.2020.25.13.2000323

7. NHS England. Clinical Guide for the Optimal Use of Oxygen Therapy During the Coronavirus Pandemic. (2020). Available online at: https://www.england. nhs.uk/coronavirus/wp-content/uploads/sites/52/2020/04/C0256-specialtyguide-oxygen-therapy-and-coronavirus-9-april-2020.pdf

8. NICE, UK. COVID-19 Rapid Guideline: Managing Suspected or Confirmed Pneumonia in Adults in the Community. NG165. (2020).

9. Sociedad Española De Neumología Y Cirugía Torácica. Recomendaciones de Consenso SEPAR - AEER Sobre la Utilidad de la Ecografía Torácica en el Manejo del Paciente con Sospecha o Infección Confirmada con COVID-19. (2020). Available online at: http://svmefr.com/wp-content/uploads/2020/03/ COVID19-SEPAR-26_03_20.pdf

10. Poston JT, Patel BK, Davis AM. Management of Critically Ill Adults With COVID-19. JAMA. Published online March 26. (2020). doi: $10.1001 /$ jama.2020.4914

11. Italian Thoracic Society. Managing the Respiratory care of patients with COVID-19. 8th March (2020). http://www.aiponet.it and http://www.siprirs.it. supplemental oxygen-delivered optimally-likely represent an appreciable modifiable factor in the bid to reduce the morbidity and mortality associated with the COVID-19 pandemic.

With regard to target oxygen saturations specifically, the evidence is clear: target oxygen saturations for the majority of people with COVID-19 remain at $94-98 \%$ [for acidotic type 2 respiratory failure see specific guidelines (25)].

\section{DATA AVAILABILITY STATEMENT}

The original contributions presented in the study are included in the article, further inquiries can be directed to the corresponding author/s.

\section{AUTHOR CONTRIBUTIONS}

DG, FM, and SB contributed to the conception and writing of the article.

12. Claudio Rabec, Jésus Gonzalez-Bermejo. Procedure for the pulmonary management of non-ICU patients hospitalized in the context of the COVID19 pandemic http://splf.fr/wp-content/uploads/2020/04/RespiPreREA-SPLFGAVO2avril2020-english-version-r.pdf

13. Vold ML, Aasebø U, Hjalmarsen A, Melbye H. Predictors of oxygen saturation $\leq 95 \%$ in a cross-sectional population based survey. Respir Med. (2012) 106:1551-1558. doi: 10.1016/j.rmed.2012.06.016

14. British Thoracic Society 2015. Annotated BTS Guideline for the Management of CAP in Adults. (2009). Available online at: https://www.brit-thoracic.org. uk/quality-improvement/guidelines/pneumonia-adults/

15. WHO, interim guidelines. Clinical management of severe acute respiratory infection when COVID-19 is suspected. March (2020). https://www.who. $\mathrm{int} /$ publications-detail/clinical-management-of-severe-acute-respiratoryinfection-when-novel-coronavirus-(ncov)-infection-is-suspected.

16. Alhazzani W, Møller MH, Arabi YM, Loeb M, Gong MN, Fan E, et al. Surviving Sepsis Campaign: guidelines on the management of critically ill adults with Coronavirus Disease 2019 (COVID-19). Intensive Care Med. (2020) 46:854-87. doi: 10.1097/CCM.0000000000004363

17. van den Boom W, Hoy M, Sankaran J, Liu M, Chahed H, Feng M, et al. The search for optimal oxygen saturation targets in critically Ill patients: observational data from large ICU databases. Chest. (2020) 157:566-73. doi: 10.1016/j.chest.2019.09.015

18. Chu DK, Kim LH, Young PJ, Zamiri N, Almenawer SA, Jaeschke R, et al. Mortality and morbidity in acutely ill adults treated with liberal versus conservative oxygen therapy (IOTA): a systematic review and meta-analysis. Lancet. (2018) 391:1693-705. doi: 10.1016/S0140-6736(18)30479-3

19. Siemieniuk RAC, Chu DK, Kim LH, Güell-Rous MR, Alhazzani W, Soccal $\mathrm{PM}$, et al. Oxygen therapy for acutely ill medical patients: a clinical practice guideline. BMJ. (2018) 363:k4169. doi: 10.1136/bmj.k4169

20. IICU-ROX Investigators the Australian New Zealand Intensive Care Society Clinical Trials Group, Mackle D, Bellomo R, Bailey M, Beasley R, Deane A, et al. Conservative oxygen therapy during mechanical ventilation in the ICU. N Engl J Med. (2020). 382:989-98. doi: 10.1056/NEJMoa1903297

21. Barrot L, Asfar P, Mauny F, Winiszewski H, Montini F, Badie J, et al. Liberal or conservative oxygen therapy for acute respiratory distress syndrome. $\mathrm{N} \mathrm{Engl} \mathrm{J}$ Med. (2020) 382:999-1008. doi: 10.1056/NEJMoa1916431

22. Girardis M, Busani S, Damiani E, Donati A, Rinaldi L, Marudi A, et al. Effect of conservative vs conventional oxygen therapy on mortality among patients in an intensive care unit: the oxygen-ICU randomized clinical trial. JAMA. (2016) 316:1583-9. doi: 10.1001/jama.2016.11993

23. Panwar R, Hardie M, Bellomo R, Barrot L, Eastwood GM, Young PJ, et al. Conservative versus liberal oxygenation targets for mechanically ventilated 
patients. a pilot multicenter randomized controlled trial. Am J Respir Crit Care Med. (2016). 193:43-51. doi: 10.1164/rccm.201505-1019OC

24. Schernthaner C, Wernly B, Lichtenauer M, Franz M, Lauten A, Schulze PC, et al. High peak $\mathrm{PaO} 2$ values associated with adverse outcome in patients treated with noninvasive ventilation for acute cardiogenic pulmonary edema and pneumonia. Panminerva Med. (2017) 59:290-6. doi: $10.23736 /$ S0031-0808.17.03370-5

25. BTS Guidance. Respiratory Support of Patients on Medical Wards. (2020). Available online at: https://www.brit-thoracic.org.uk/about-us/covid-19information-for-the-respiratory-community/

26. Roche F, Reynaud C, Pichot V, Duverney D, Costes F, Garet M, et al. Effect of acute hypoxia on QT rate dependence and corrected QT interval in healthy subjects. Am J Cardiol. (2003) 91:916-9. doi: 10.1016/S0002-9149(03)00040-7

27. Fröhlich S, Boylan J, McLoughlin P. Hypoxia-induced inflammation in the lung: a potential therapeutic target in acute lung injury?. Am J Respir Cell Mol Biol. (2013) 48:271-9. doi: 10.1165/rcmb.2012-0137TR

28. Gonzalez NC, Wood JG. Alveolar hypoxia-induced systemic inflammation: what low PO(2) does and does not do. Adv Exp Med Biol. (2010) 662:27-32. doi: 10.1007/978-1-4419-1241-1_3

29. Jha PK, Sahu A, Prabhakar A, Tyagi T, Chatterjee T, Arvind P, et al. Genomewide expression analysis suggests hypoxia-triggered hyper-coagulation leading to venous thrombosis at high altitude. Thromb Haemost. (2018) 118:1279-95. doi: 10.1055/s-0038-1657770

30. Børvik T, Evensen LH, Morelli VM, Melbye H, Brækkan SK, Hansen JB. Impact of respiratory symptoms and oxygen saturation on the risk of incident venous thromboembolism-the Tromsø study. Res Pract Thromb Haemost. (2020) 4:255-62. doi: 10.1002/rth2.12299

31. Michiels C. Physiological and pathological responses to hypoxia. Am J Pathol. (2004) 164:1875-82. doi: 10.1016/S0002-9440(10)63747-9

32. Hu WP, Zhang FY, Zhang J, Hang JQ, Zeng YY, Du CL, et al. Initial diagnosis and management of adult community-acquired pneumonia: a 5-day prospective study in Shanghai. J Thorac Dis. (2020) 12:1417-26. doi: $10.21037 /$ jtd.2020.03.02

33. Blot SI, Rodriguez A, Solé-Violán J, Blanquer J, Almirall J, Rello J, CommunityAcquired Pneumonia Intensive Care Units (CAPUCI) Study Investigators. Effects of delayed oxygenation assessment on time to antibiotic delivery and mortality in patients with severe community-acquired pneumonia. Crit Care Med. (2007) 35:2509-14. doi: 10.1097/01.CCM.0000287587.43801.9C

34. Shenoy N, Luchtel, R. \& Gulani, P. Considerations for target oxygen saturation in COVID-19 patients: are we under-shooting?. BMC Med. (2020) 18:260. doi: 10.1186/s12916-020-01735-2

35. Ackermann M, Verleden SE, Kuehnel M, Haverich A, Welte T, Laenger F, et al. Pulmonary vascular endothelialitis, thrombosis, and angiogenesis in covid-19. N Engl J Med. (2020) 383:120-8. doi: 10.1056/NEJMoa 2015432
36. Carsana L, Sonzogni A, Nasr A, Rossi RS, Pellegrinelli A, Zerbi P, et al. Pulmonary post-mortem findings in a series of COVID-19 cases from northern Italy: a two-centre descriptive study. Lancet Infect Dis. (2020) 20:1135-40. doi: 10.1016/S1473-3099(20)30434-5

37. Bryce C, Grimes Z, Pujadas E, Ahuja S, Beasley MB, Albrecht R, et al. Pathophysiology of SARS-CoV-2: targeting of endothelial cells renders a complex disease with thrombotic microangiopathy and aberrant immune response. The Mount Sinai COVID-19 autopsy experience. medRxiv [Preprint]. (2020). doi: 10.1101/2020.05.18.20099960

38. Austrian Society of Pneumology. Stellungnahme der ÖGP zum Management von akuten SARS-CoV-2 Infektionen und zum Management von chronischen Lungenerkrankungen während der SARS-CoV-2 Pandemie. Vienna.

39. Menter T, Haslbauer JD, Nienhold R, Savic S, Hopfer H, Deigendesch N, et al. Postmortem examination of COVID-19 patients reveals diffuse alveolar damage with severe capillary congestion and variegated findings in lungs and other organs suggesting vascular dysfunction. Histopathology. (2020) 77:198-209. doi: 10.1111/his.14134

40. Sun Q, Qiu H, Huang M, Yang Y. Lower mortality of COVID-19 by early recognition and intervention: experience from Jiangsu Province. Ann Intensive Care. (2020) 10:33. doi: 10.1186/s13613-020-00650-2

41. O'Driscoll BR, Howard LS, Earis J, Mak V. British Thoracic Society Guideline for oxygen use in adults in healthcare and emergency settings. BMJ Open Respir Res. (2017) 4:e000170. doi: 10.1136/bmjresp-2016-000170

42. Wilkerson RG, Adler JD, Shah NG, Brown R. Silent hypoxia: a harbinger of clinical deterioration in patients with COVID-19. Am J Emerg Med. (2020) 38:2243.e5-2243.e6. doi: 10.1016/j.ajem.2020.05.044

43. Ministry of Health, Singapore. Comprehensive Medical Strategy For Covid19. Available online at: https://www.moh.gov.sg/news-highlights/details/ comprehensive-medical-strategy-for-covid-19

44. Swiss Society of Intensive Care Medicine. Recommendations for the Admission of Patients With COVID-19 to Intensive Care and Intermediate Care Units (ICUs and IMCUs). Swiss Med Wkly. (2020). 150:w2022 doi: $10.4414 /$ smw.2020.20227

Conflict of Interest: The authors declare that the research was conducted in the absence of any commercial or financial relationships that could be construed as a potential conflict of interest.

Copyright (c) 2021 Goyal, Mansab and Bhatti. This is an open-access article distributed under the terms of the Creative Commons Attribution License (CC BY). The use, distribution or reproduction in other forums is permitted, provided the original author(s) and the copyright owner(s) are credited and that the original publication in this journal is cited, in accordance with accepted academic practice. No use, distribution or reproduction is permitted which does not comply with these terms. 